\title{
Prevention and treatment of impairment in doctors
}

\section{Kay Wilhelm, Michael Diamond \& Anthony Williams}

This paper will concentrate on some of the practical contributions that consultant psychiatrists can make in the prevention and treatment of psychiatric impairment in doctors. We will illustrate this with case material from programmes in which there has been a good deal of psychiatrist participation.

\section{Importance of career stage}

The medical career has its own 'life cycle' with a number of stages. A student doctor, learning the tools of the trade, graduates to become a novice doctor, starting out as an intern and acquiring skills as a clinician and communicator. Having acquired the necessary experience and qualifications, the more mature doctor continues to learn in an ongoing process as skills need to be updated, while acting also as teacher and mentor (as a senior member of a practice or department), intervening with institutions and other august bodies, empowering and enthusing others, training others and providing a role model. Finally, there is the older doctor who is planning for retirement and 'winding down'.

The types of intervention needed tend to vary over these stages. Prevention and early intervention are more prominent needs for younger doctors, while assessment and treatment take precedent in older doctors, with the overall premise of 'the earlier the better'. Issues of impairment become increasingly relevant over time, and the effects of such impairment tend to be cumulative - for doctors, their patients and their professional and social networks.

\section{Student and novice doctors}

A recent survey of 126 American medical schools (Hays et al, 1996) noted that most suicides were of men and two-thirds of successful suicides were of students who had a previous psychiatric history. The authors drew attention to the need to devote attention to the "emotional development ... as well as the development of his or her medical skills", and noted that:

the issue of suicide and vulnerability to stress should not be left to the psychiatry department but dealt with at all levels of the medical school experience.

A five-year study in a Sydney teaching hospital (Hume \& Wilhelm, 1994) found that most of the students chose to study medicine for reasons of altruism ("to help people"), job security and academic stimulation. The 130 interns were asked for their ideas on helpful strategies for survival in the early years as a doctor, and suggested the following: having clear career goals; making full use of leisure time; valuing and working to maintain personal support systems; taking care of oneself; listing questions to ask senior staff; listening to advice from experienced nursing staff; and being assertive with other medical staff and the medical administration (including learning to

Kay Wilhelm is a consultant psychiatrist and clinical director of a teaching hospital psychiatry unit, director of training for a regional health service, and holds a conjoint academic position at the University of New South Wales (Caritas Centre, 299 Forbes Street, Darlinghurst, Sydney, New South Wales 2010). She is involved in research concerning the mental health of young doctors and has been a member of various Impaired Registrants' Panels, Professional Standards Committees and Medical Tribunals for the NSW Medical Board. Michael Diamond is a consultant psychiatrist with experience in private practice, organisation of a registrar training programme and teaching. He works with the NSW Medical Board as a consultant psychiatrist to assist in the running of the Impairment Programme. Tony Williams is Director of the NSW Institute of Psychiatry. He has extensive experience in public health psychiatry, cross-cultural psychiatry and mental health education. Since 1987, he has been the nominee of the Royal Australian and New Zealand College of Psychiatrists on the Medical Board of NSW. He is a member of a NSW Health Department committee advising on the mental health and well-being of doctors. 
insist on help when required, and delegating to others).

At the start of their intern year, $17 \%$ reported having sought help for previous emotional problems (half sought assistance once only, the other half sought ongoing assistance). Seven per cent had sought help for anxiety problems, $5 \%$ for depression and about $10 \%$ (all women) acknowledged eating disorders. The interns tended to cope quite well in terms of self-reported levels of distress. At the end of the year, $8 \%$ reported seeking help during the year (again, about half on an occasional basis only). Those seeking regular help reported anxiety, depression and eating disorders as their main concerns. In the year, $4 \%$ of the group had "often" considered life was not worth living and 3\% had entertained (but not acted on) suicidal plans. Importantly, $72 \%$ of the group reported "often" experiencing significant (and personally distressing) episodes of anger during the intern year.

An English study of house officers (Dowling \& Barrett, 1991) found that these novice doctors maintained the risk factors they had developed before graduating from medical school, and incurred further stress from sleep deprivation, overwork and disillusionment during their first postgraduate year. Clearly, expressions of anger are also likely in these circumstances.

\section{Prevention of impairment}

These findings indicate the need for more attention to anger-management and time-management skills during the intern year. However, these will only be meaningful if taken seriously by the medical establishment and if junior staff are released from normal duties to attend such sessions. Students and novice doctors are often apprehensive about seeking help for their own emotional needs. They fear that their careers might be prejudiced by acknowledgement of their impairment and that expression of anger and distress could be viewed as signs of personal weakness. They are also busy and resent intrusions into their personal time. However, the emphasis on teaching communication skills is gaining momentum and the interpersonal benefits persist (Maguire et al, 1986; Price \& Miflin, 1994).

Psychiatrists should highlight these issues with those responsible for the welfare of novice doctors, and emphasise the importance of early intervention. They should ensure that help is available, and encourage the production of educational material as adjuncts to personal communication in this area. Overseas-trained doctors have been found to be particularly vulnerable to deficits in communication skills (Rolfe \& Pearson, 1996) and may require additional assistance. We also note the importance of developing suitable career paths for doctors who are significantly impaired, as doctors often are ill-prepared for non-medical careers.

Psychiatrists also have the training to be aware of other 'at risk' indicators such as vulnerable personality styles, early signs of depression, eating disorders and drug and alcohol misuse. These issues are often raised as questions at the end of undergraduate lectures or during placements in psychiatry units, when young doctors become aware that their symptoms have a name or that effective interventions are available. This can provide valuable 'windows of opportunity'. We have developed a series of vignettes for use in teaching sessions with medical students and novice doctors focusing on issues likely to lead to expressions of anger and frustration and other frequent interpersonal and ethical problems (see Box 1).

Box 1 Vignettes for discussion with medical students and novice doctors

You are worried about a fellow intern: he has stopped socialising; he is spending more time in his room; he is drinking more, sleeping in and missing breakfast. His work performance has slipped and he has been uncharacteristically rude to nurses. There are rumours of problems with his family and his relationship with his girlfriend is deteriorating. What do you do?

You have been caring for a young, attractive patient with an uncomplicated appendicitis. The day after discharge, the patient returns with an expensive gift, a card containing a contact number and invitations to (a) drinks at a local club; (b) a 'recovery' party at home in two weeks' time; and (c) a concert of a group you'd love to see. What is your response to each alternative?

You are the medical intern covering a number of wards. While admitting and treating a man with severe asthma, you are paged by a nurse from another ward asking you to come immediately. A man is in the throes of acute withdrawal from alcohol, on his second post-operative day following a laparotomy. He has become increasingly agitated during visiting hours and is insisting on signing himself out. What do you do? 
Box 2 Questions related to impairment from the Royal Australian and New Zealand College of Psychiatrists consultancy examination

You are working as a consultant in a teaching hospital. One of your registrars tells you that he is concerned about a resident medical officer whose work is deteriorating. A patient has informed him that the doctor has occasionally had slurred speech and has 'track-marks' on his forearms. What would you do?

You are a consultant psychiatrist in private practice treating a medical colleague for depression. What symptoms and signs would alert you to the fact that the doctor's level of depression might be impairing his/her ability to practice? What could you do?

You have been informed by one of the nursing staff that the registrar you supervise has been spending long periods of time with a patient who comes to the psychiatry day hospital. She is receiving psychotherapy from that registrar. How would you approach this problem?

Consultant psychiatrists are also ideally placed to educate other senior medical staff about the benefits of these strategies and to encourage presentation of such topics in the medical curriculum and during early postgraduate training. Basic communication and anger-management skills are useful for dealing with the first two postgraduate years and can be taught in the undergraduate curriculum. Two of us (A.W. and K.W.) have been involved with such teaching to undergraduates and postgraduates and find it rewarding and interesting. A common fear expressed is the erosion of academic knowledge gained as undergraduates during the early postgraduate years, and we also stress that the sorts of lessons learnt as a novice doctor include increased awareness of one's own interpersonal strengths and difficulties and that such knowledge is a valuable part of medical experience ('making one a better doctor'). However, attention also needs to be given to ongoing needs for academic stimulation by providing didactic material to backup these personal experiences and allowing the opportunity to ventilate concerns. By stressing the importance of emotional ventilation and the need to 'look after one's self', we are hopefully laying foundations for good habits.

Questions on impairment are asked in the halfhour consultancy viva examination which is part of the final group of examinations for entry into the Royal Australian and New Zealand College of Psychiatrists. Candidates are asked to address three vignettes pertaining to roles that a psychiatrist plays apart from the direct clinical role. Examples of questions relating to impairment in colleagues are given in Box 2. Frequent inclusion of such questions implies that the issues are important and ensures that they will be included in pre-exam discussion.

\section{The later years}

A recent random survey of doctors on the NSW Medical Register (Pullen et al, 1995) sought to describe doctors' attitudes to their own health care. While the responders tended to comprise an overrepresentation of more senior doctors, the age and gender distributions reflected the expected rates of sociodemographic variables. Of the doctors surveyed, $26 \%$ had a condition warranting medical consultation; $19 \%$ reported marital disturbances, $18 \%$ emotional disorders; and 3\% had alcohol problems. Only $42 \%$ had their own general practitioner and many of those who did had not discussed these problems. The authors recommended that an integral part of doctors' initial and ongoing medical education should be to learn appropriate strategies to allow them to seek help for themselves. With the development of continuing education, which often involves self-assessment, it is possible to ensure the inclusion of questions related to these issues.

\section{Psychiatric treatment of impaired doctors}

Doctors are known to have difficulty seeking help for themselves and in placing themselves in the patient role (Pullen et al, 1995). By not seeking proper assistance and by self-prescribing inappropriately, impaired doctors can place their patients, as well as themselves, at risk. There are many reasons why doctors fail to seek help. These include seeing themselves as too busy; not taking the same care of themselves as they do of their patients; not having their own general practitioner (Lonie et al, 1994); and, 
Table 1 Common problems presenting at various stages in a medical career

\begin{tabular}{|c|c|c|c|c|}
\hline & $\begin{array}{l}\text { Medical student, } \\
\text { late teens to } 24\end{array}$ & $\begin{array}{l}\text { Novice doctor, } \\
25 \text { to } 34\end{array}$ & $\begin{array}{l}\text { Mature doctor, } \\
35+\end{array}$ & $\begin{array}{l}\text { Older doctor, } \\
55+\end{array}$ \\
\hline $\begin{array}{l}\text { Common } \\
\text { problems }\end{array}$ & $\begin{array}{l}\text { Adjustment to course } \\
\text { Anxiety and somatoform } \\
\text { disorders } \\
\text { Depression } \\
\text { Substance misuse } \\
\text { Early psychosis }\end{array}$ & $\begin{array}{l}\text { Adjustment to hospital } \\
\text { Anxiety and somatoform } \\
\text { disorders } \\
\text { Depression } \\
\text { Substance and alcohol } \\
\text { misuse }\end{array}$ & $\begin{array}{l}\text { Depression } \\
\text { Alcohol and substance } \\
\text { misuse/dependence } \\
\text { Marital problems }\end{array}$ & $\begin{array}{l}\text { Depression } \\
\text { Early physical and } \\
\text { cognitive decline } \\
\text { Alcohol dependence } \\
\text { Delusional disorder }\end{array}$ \\
\hline Complaints & $\begin{array}{l}\text { Inappropriate behaviour } \\
\text { in clinical setting } \\
\text { Impaired performance }\end{array}$ & $\begin{array}{l}\text { Inappropriate behaviour } \\
\text { in clinical setting } \\
\text { Impaired performance } \\
\text { Substance misuse }\end{array}$ & $\begin{array}{l}\text { Inappropriate behaviour } \\
\text { in clinical setting } \\
\text { Substance and alcohol } \\
\text { misuse } \\
\text { Sexual indiscretion }\end{array}$ & $\begin{array}{l}\text { Inappropriate behaviour } \\
\text { in clinical setting } \\
\text { Impaired performance } \\
\text { Substance misuse } \\
\text { Sexual indiscretion }\end{array}$ \\
\hline Who notices & $\begin{array}{l}\text { Lecturers and supervisors } \\
\text { Fellow students } \\
\text { Own doctor }\end{array}$ & $\begin{array}{l}\text { Patients and their families } \\
\text { Clinical supervisors } \\
\text { Medical administrators } \\
\text { Own doctor } \\
\text { Official complaints }\end{array}$ & $\begin{array}{l}\text { Colleagues } \\
\text { Family and friends } \\
\text { Own doctor } \\
\text { Official complaints }\end{array}$ & $\begin{array}{l}\text { Patients and their familes } \\
\text { Colleagues } \\
\text { Family and friends } \\
\text { Own doctor } \\
\text { Official complaints }\end{array}$ \\
\hline Who assesses & $\begin{array}{l}\text { Member of faculty } \\
\text { Student counselling unit } \\
\text { Own doctor } \\
\text { Medical Board } \\
\text { Board-nominated } \\
\text { psychiatrist }\end{array}$ & $\begin{array}{l}\text { Clinical supervisor } \\
\text { Own doctor } \\
\text { Doctors' counselling } \\
\text { service } \\
\text { Medical Board } \\
\text { Board-nominated } \\
\text { psychiatrist }\end{array}$ & $\begin{array}{l}\text { Own doctor } \\
\text { Doctors' counselling } \\
\text { service } \\
\text { Medical Board } \\
\text { Board-nominated } \\
\text { psychiatrist }\end{array}$ & $\begin{array}{l}\text { Own doctor } \\
\text { Doctors' counselling } \\
\text { service } \\
\text { Medical Board } \\
\text { Board-nominated } \\
\text { psychiatrist }\end{array}$ \\
\hline Who treats & $\begin{array}{l}\text { Student counselling unit } \\
\text { Own doctor } \\
\text { Clinicians with } \\
\text { undertakings to Board }\end{array}$ & $\begin{array}{l}\text { Own doctor } \\
\text { If formally, } \\
\text { clinicians with } \\
\text { undertakings to Board }\end{array}$ & $\begin{array}{l}\text { Own doctor } \\
\text { If formally, } \\
\text { clinicians with } \\
\text { undertakings to Board }\end{array}$ & $\begin{array}{l}\text { Own doctor } \\
\text { If formally, } \\
\text { clinicians with } \\
\text { undertakings to Board }\end{array}$ \\
\hline
\end{tabular}

particularly for those who are self-employed, not wishing to take time off work because of the administrative and financial costs involved.

Most impaired doctors who seek treatment initially go though similar procedures to their patients, although frequently greater effort has gone into keeping them away from psychiatrists and mental health services. Apart from the usual health care network available to the general public, doctors have access to informal consultations by talking to a professional colleague or supervisor and, potentially at least, increased access to information. We have outlined (Table 1) the likely reasons for referral, modes of assessment and treatment for doctors at various stages of their medical career.

\section{NSW Impaired Doctors' Programme}

Prior to 1992, the NSW Medical Board operated under the provisions of the Medical Practitioners'
Act 1938, which only provided options for disciplining doctors who came to the Board's attention in respect of matters of impairment, and had no power to impose conditions without a formal hearing. This system was similar to the current situation in the UK.

During the late 1980s, the Board developed an informal programme in which impaired doctors undertook voluntarily to be monitored regularly (in the form of routine reports from a Boardnominated psychiatrist and/or physician) and given review interviews with the Board. This process evolved into the Board's rehabilitation programme, which was embodied in the Medical Practice Act 1992.

Impaired doctors are brought before the Board under non-disciplinary Impaired Registrants' Panels (IRPs; see Fig. 1) and the doctor is able to acknowledge his/her problem and enter into a treatment and monitoring programme in a spirit of cooperation, but with legislative back-up which enables the Board to insist that impaired doctors receive appropriate assessment and treatment.

We describe the NSW model in some detail for a number of reasons. First, there has been very 
significant input from consultant psychiatrists to the development and implementation of the programme, which has been strongly encouraged by the local Medical Board. Second, the principles of providing structured management plans with clear guidelines and end-points, including builtin requirements for feedback and review, are vitally important in providing a firm, but treatmentcontaining, context for the impaired doctor. Third, whereas previously, treatment was considered to be less successful because it was paternalistic, lacked structure, provided few options for treatment and rehabilitation, and had no 'teeth', there has been widespread interest in the current programme which allows the Board to be involved with impaired doctors in a manner that is independent of disciplinary or competency matters.

We have noted that the types of impairment notified vary at different stages of the medical career but are overwhelmingly related to psychiatric disorders and substance misuse. In terms of age groups, $13 \%$ are in their $20 \mathrm{~s}, 63 \%$ in their $30 \mathrm{~s}$ and 40 s, and $24 \%$ are 50 and over. There is some age-related variation in disorders; psychiatric presentations are spread through the 20- to 40-year age groups, most drug self-administration manifests in the 30s and 40s, while alcohol abuse manifests slightly later.
It is clear that doctors in their 30 s and 40 s (novice and maturing doctors) are more likely to present to the Board. This is important to remember as these are the years when doctors can be considered to be reaching their 'prime' and are expending maximum energy in both career development and establishing homes and families.

There appears to be an under-reporting of alcohol misuse and cognitive impairment (both of which would have a later mean age of presentation). Indeed, there is not much notification of older doctors in general. We speculate that reasons for such lack of notification include: lack of subjective insight by the impaired doctor; lack of recognition of severity of both cognitive decline and alcohol misuse by colleagues; and more propensity for the impaired doctor's colleagues to address the problem 'in-house' or overlook it as being less potentially dangerous. Also, detection technology for alcohol dependence has not been as well developed as for the commonly self-administered drugs.

Brooke's study (1995) of English doctors with addiction problems also noted that few doctors could be identified during student or early postgraduate years as the vast majority of problems came to light only after many years when individual vulnerabilities were more apparent.

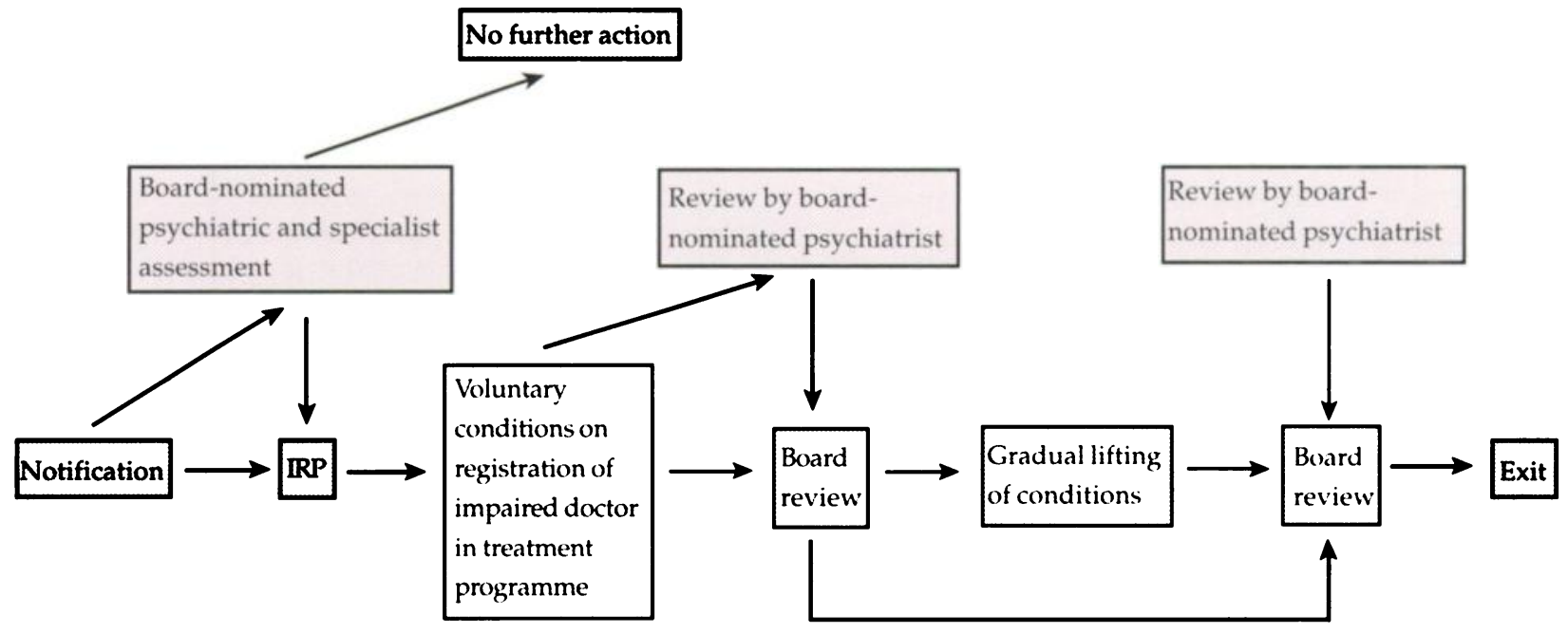

Equivalent process in standard medical care

Presentation $\longrightarrow$ Assessment $\longrightarrow$ Consultation $\longrightarrow$ Management plan $\longrightarrow$ Monitoring and revisits 


\section{Roles for consultant psychiatrists}

In terms of standard medical care, psychiatrists may act as treating doctors following self-referral from the impaired doctor or referral from another doctor through standard channels. In the case of novice doctors, they may also be approached through a training body (by student counsellors, more senior staff or directors of training).

The NSW Impaired Registrants' Programme provides many roles for psychiatrists. There is a Board-appointed psychiatrist who reviews all new referrals, separates health from disciplinary matters, recommends further action for each referral, and makes a clinical assessment prior to a doctor's appearance before Board-appointed interviews. A psychiatrist also chairs the Board's Health Committee which monitors progress and approves changes in treatment of impaired doctors in the programme. There are a number of Boardappointed psychiatrists who provide periodic reports to the Medical Board and they are not involved in the clinical treatment of the impaired doctors. Psychiatrists also act as members of the various bodies that are convened to assess impaired doctors.

\section{Case examples}

\section{Referral after involuntary psychiatric admission}

Dr A. is a 38-year-old GP who was formally notified to the Board as a result of an involuntary admission to a psychiatry unit (a requirement under the Act). When he had recovered from that episode, he was asked to see a Board-nominated psychiatrist whose assessment report detailed a six-year history of a poorly controlled depressive illness, with sporadic antidepressant prescription from a psychiatrist friend. The index admission had followed a manic episode that the friend had been unable to contain.

The psychiatrist at the Board interview found that there was a significant family history of bipolar disorder and the impaired doctor expressed his fears about the effect of this illness on himself and his ability to practise. The impaired doctor agreed to the following conditions: to see a psychiatrist (not a friend) for treatment as determined by the clinician, and inform the Board of arrangements; to inform his partner in practice of his condition; and to see a Board-nominated psychiatrist for assessment prior to a Board review in six months.

The doctor settled into regular treatment and over the next six months there were fewer mood swings, with a mild hypomanic episode managed as an outpatient. The periods of review lengthened over the ensuing years and he has conditional registration contingent on annual Board review, which is likely to continue indefinitely.

\section{'Self-referral' after self-administration of a} narcotic

Dr B. is a 46-year-old GP who 'self-referred' following a visit from an officer from the state prescribing authority. An investigation discovered an eight-month history of pethidine self-administration. Ten years ago she had her prescribing rights for narcotics withdrawn and then reinstated four years later. Previous contact with the Board (under the old system) had involved voluntary undertakings with no urinary drug monitoring.

A report from a Board-nominated psychiatrist, with a special interest in substance misuse, revealed a 10-year history of lower back pain self-treated with oral narcotics and benzodiazepine, and pethidine use after marital separation and financial problems. Dr B. entered a detoxification centre and was drug-free for eight weeks prior to the IRP where she agreed: to not self-prescribe and have urinalysis three times a week; to see a psychiatrist for treatment of substance misuse; to inform the Board of the name of the psychiatrist and frequency of attendance; to attend a pain clinic and a doctors' Narcotics Anonymous group; to inform the principal in her practice; and to attend an assessment by a Boardnominated psychiatrist prior to a Board review in six months.

There was an initial stormy three months with numerous breeches of benzodiazepine self-administration but dramatic improvement occurred following a four-week out-patient pain management programme, with abstinence reinforced by Narcotics Anonymous. After 12 months' regular urinalysis she progressed to random urinalysis and after four years, she had a partial reinstatement of prescribing rights with the prospect of exit from the programme after her next review.

\section{Referral following complaints}

$\mathrm{DrC}$. is a 28-year-old resident medical officer from a busy city hospital. Notification followed a number of complaints from hospital staff of erratic behaviour (not turning up to work and being short-tempered and irritable with patients) and finally, being found comatose at work with an intravenous line in situ. He acknowledged injecting insulin with suicidal intent and was admitted for assessment. He then had out-patient psychotherapy, which he found helpful. He was reviewed by a Board-nominated psychiatrist four months after the overdose and stated that the incidents had occurred after he discovered he was HIV-positive and had told his father who was very angry and rejecting. He had become involved with HIV-orientated support services and was in a stable relationship with a supportive partner. His subsequent return to work was incident-free.

The psychiatrist member of the IRP found that he was completely asymptomatic from the HIV perspective, was working competently and had completely recovered from his depressive episode. He was continuing to see his psychiatrist to explore his personality vulnerabilities and coping styles. No 
undertakings were made other than agreement to annual review by the Board to monitor progress.

\section{Successes and failures of the Impaired Doctors' Programme}

The programme was most successful in rehabilitation and monitoring of those with mood disorders, obsessive-compulsive disorders, drug and alcohol dependence and those with anxious and dependent personality styles. It has been less successful for borderline, antisocial and paranoid personality disorders. For doctors with the latter personality styles, and some with substance misuse, there is often a point at which decisions need to be made about the desirability of persisting with the impairment programme or making a referral to the disciplinary arm. For those with psychotic disorders, the degree of insight is clearly important.

\section{Issues for psychiatrists dealing with impaired doctors}

The treatment of impaired doctors is challenging and predominantly involves disorders that are psychiatric or have psychiatric implications. Those who are impaired are clever, skilled verbally and can be intimidating to those who are not used to treating medical colleagues. They are knowledgeable and can easily slip into the use of medical jargon. They can use their knowledge to mask symptoms by self-medicating (either appropriately or inappropriately). They know which of their colleagues may be a 'soft option' when seeking treatment for themselves and do not easily engage in psychotherapy. They can be dishonest with the treating psychiatrist and themselves, and can collude with the treating psychiatrist to lose sight of the fact that the impaired doctor is the patient.

Often, it is suicide attempts in doctors that bring impairment issues to the forefront. The suicidal doctor may have signalled their intention previously and may exhibit some characteristic behaviour patterns before an attempt, including depression, self-doubt about ordinary medical practices, excessive tension with difficult diagnostic problems, and neglect of practice (Arana, 1982; Council on Scientific Affairs, 1987). Doctors also have the prerequisite knowledge to successfully complete suicide, which further emphasises the importance of identification of stress and depression leading to suicidal intent.
An American Medical Association report on their Impaired Physician Movement (Sargent, 1985) noted that:

psychiatrists must continue to play a role in the work that lies ahead ... without our leavening presence, programmes begun with benevolent intent easily veer into sterile discipline, or can become paternalistic.

Psychiatrists can make valuable contributions in the standard treatment process and in developing assertive and proactive formal treatment programmes. Their special contribution lies in their ability to take complex histories integrating biological, psychological and social factors in a systemic framework; to evaluate and synthesise conflicting information issues; to be sceptical; and to advise on appropriate limit-setting.

These issues are easier to grapple with when there is clear impairment and a request for treatment (whether voluntary or otherwise). However, we have also talked of roles for psychiatrists in the more problematic sphere of prevention of impairment. Wold \& Karlin (1994) have noted that obsessional personality traits are often rewarded in medicine and note that "difficult emotions are dissected away leaving the rational approach", which can be adaptive in dealing with suffering in others. However:

while these traits work well in achieving professional goals, they can wreak havoc with a marriage ... staff may have their feelings ignored ... it can become a setup for unhappiness, stress and ultimately major depression and psychosomatic disorders.

Wold \& Karlin (1994) suggest that psychiatrists have particular skills in identifying vulnerable personality styles, which may become more apparent at times of crisis (whether personal or work problems) and advocate that psychiatrists consider using their knowledge of psychotherapeutic techniques to ameliorate crises and modify characteristic patterns. They also point out that most doctors are reluctant to perceive problems in respected colleagues and we would expect that mature doctors are likely to report having 'little time' for their own personal needs and are unlikely to acknowledge the need for early intervention themselves. There are also privacy and ethical considerations. However, one must be mindful that phenomena manifesting in junior staff such as repeated outbursts of anger, uncharacteristic and unexplained changes in work practices, depression, and eating disorders may be 'early warning signs', which if unattended, lead to problems such as self-medication or suicide.

In highlighting some of the preventive aspects we do not mean to imply that psychiatrists should 
be their 'brother's keepers' but to emphasise the need to keep prevention and early intervention as issues that are automatically considered, rather than as unusual considerations. At times, proactive intervention may be required. Wold \& Karlin (1994) draw the analogy that it is not kindness to let an early tumour go unnoticed and untreated. We concur with their conclusion that psychiatric disorders are treatable and "early intervention can save both families and careers".

\section{References}

Arana, G. W. (1982) The impaired physician: a medical and social dilemma. General Hospital Psychiatry, 4, 147-154.

Brooke, D. (1995) The addicted doctor. British Journal of Psychiatry, 166, 149-153.

Council on Scientific Affairs (1987) Results and implications of the AMA-APA physician mortality project. Stage II. Journal of the American Medical Association, 257, 2949-2953.

Dowling, S. \& Barrett, S. (1991) Doctors in the Making. The Experience of the Pre-Registration Year. Bristol: SAUS Publications.

Hays, L. R., Cheever, R. T. \& Patel, P. (1996) Medical student suicide, 1989-1994. American Journal of Psychiatry, 153, 553-555.

Hume, F. \& Wilhelm, K. (1994) Career choice and experience of distress amongst interns. Australian and New Zealand Journal of Psychiatry, 28, 319-327.

Lonie, C. E., Lyle, D. M., Pullen, D., et al (1994) Doctors' health care. A Report for the Doctors' Health Advisory Service. Sydney: DHAS.

Maguire, P., Fairbairn, S. \& Fletcher, C. (1986) Consultation skills of young doctors: benefits of training in interviewing as students persist. British Medical Journal, 292, 1573-1578.

Price, D. \& Miflin, B. (1994) Teaching the teachers: a new approach to facilitating learning in student-patient interactions. Medical Journal of Australia, 161, 181.

Pullen, D., Lonie, C. E., Lyle, D. M., et al (1995) Medical care of doctors. Medical Journal of Australia,162, 481-484.

Rolfe, I. E. \& Pearson, S. A. (1996) Screening recommendations in general practice: a survey of graduates from different medical schools. Medical Journal of Australia, 165, 14-17.

Sargent, D. A. (1985) The impaired physician: An interim report. Hospital and Community Psychiatry, 36, 294-297.

Wold, P. \& Karlin, S. (1994) Psychiatric issues in physician impairment. Rhode Island Medicine, 77, 351-353.

\section{Multiple choice questions}

1. There is little need to be concerned about early intervention with impaired doctors because:

a they will generally have insight into their own problems and seek help when needed

$b$ there is nothing that can be done

c doctors have very low rates of psychiatric impairment

d Not true. Early intervention is the best approach and can save lives and careers.
2. The most common age of notification of psychiatric impairment in doctors is in:

a their 30 s and $40 \mathrm{~s}$

b their 40 s and 50 s

c their $50 \mathrm{~s}$ and $60 \mathrm{~s}$

$\mathrm{d}$ their $60 \mathrm{~s}$ and $70 \mathrm{~s}$.

3. Helpful strategies for survival of the early years as a doctor include:

a making full use of leisure time

b valuing and working to maintain personal support systems

c listening to advice from experienced nursing staff

d getting drunk regularly.

4. Psychiatrists have a special contribution to make in dealing with impaired doctors because of their ability to:

a take complex histories integrating biological, psychological and social factors in a systemic framework

b give advice on how impaired doctors can disguise psychiatric symptoms and continue working regardless

c evaluate and synthesise conflicting information

$\mathrm{d}$ be sceptical and to advise on appropriate limit-setting

5. The NSW Impaired Doctors' Programme has been most successful in the rehabilitation and monitoring of impaired doctors with:

a anxious and dependent personality styles

b mood disorders

c obsessive-compulsive disorder

d drug and alcohol dependence.

\begin{tabular}{|c|c|c|c|c|}
\hline \multicolumn{5}{|c|}{ MCQ answers } \\
\hline 1 & 2 & 3 & 4 & 5 \\
\hline a $F$ & a $\mathrm{T}$ & a $T$ & a $\mathrm{T}$ & a $\mathrm{T}$ \\
\hline b F & b F & b $\mathrm{T}$ & b F & b $\mathrm{T}$ \\
\hline c F & c $\mathrm{F}$ & c $\mathrm{T}$ & c $\mathrm{T}$ & c $\mathrm{T}$ \\
\hline d $\mathrm{T}$ & d F & d F & d $\mathrm{T}$ & d $T$ \\
\hline
\end{tabular}

